\title{
Field Study for PAH Absorption Performances of Butyl Rubber, PDMS, and SPMD Passive Samplers
}

\section{Oktay Eren Tureyen ( $\nabla$ tureyen@itu.edu.tr )}

Istanbul Technical University: Istanbul Teknik Universitesi https://orcid.org/0000-0003-2346-1128

\section{Sevil Deniz Yakan}

Istanbul Technical University - Ayazaga Campus: Istanbul Teknik Universitesi

\section{Atilla Yilmaz}

TUBITAK MAM: Tubitak Marmara Arastirma Merkezi

\section{Berkant Yetiskin}

Istanbul Technical University - Ayazaga Campus: Istanbul Teknik Universitesi

\section{Oguz Okay}

Istanbul Technical University - Ayazaga Campus: Istanbul Teknik Universitesi

\section{Oya S. Okay}

Istanbul Technical University - Ayazaga Campus: Istanbul Teknik Universitesi

\section{Research Article}

Keywords: PAH, passive sampler, PDMS sampler, SPMD sampler, pollution monitoring

Posted Date: December 13th, 2021

DOI: https://doi.org/10.21203/rs.3.rs-1089623/v1

License: (c) (i) This work is licensed under a Creative Commons Attribution 4.0 International License. Read Full License 


\section{Abstract}

Polycyclic aromatic hydrocarbons (PAHs) are organic pollutants having various adverse effects on the marine ecosystem. Because of their low solubility in the marine environment, their detection and monitoring in the water column are challenging tasks. Passive samplers are used to detect PAHs in aquatic environments as complementary tools to conventional water sampling. In the present study, PAH absorbance performances of four butyl rubber-based (BR) passive samplers with different structures (SN5, SN10, DN, and TN) and commercialized passive samplers (SPMD and PDMS) were determined. Stainless steel cages containing passive samplers were deployed in the water column in Istinye Bay, Istanbul, and retrieved after 7 and 28 days. Collected samplers were analyzed in the laboratory to determine their PAH contents. Results showed that, even though the SPMD samplers had the highest total PAH content, they were not able to collect PAHs with log $\mathrm{K}_{\mathrm{ow}}$ value of above 6.0. Similarly, PAHs with log $\mathrm{K}_{\mathrm{ow}}$ values higher than 5.5 could have not been collected by PDMS samplers. In contrast, BR-based passive samplers have sampled also high molecular weight PAHs in the water column, and SN10 sampler showed the highest performance in terms of the collected PAHs. Results highlighted that SN10 sampler has a wide absorption range when it is compared with the commercialized samplers, and it has also advanced absorption performance relative to the other BR samplers.

\section{Introduction}

Polycyclic aromatic hydrocarbons (PAHs) are persistent and hazardous organic compounds consisting of two or more benzene rings, existing in different matrices at the same time like atmosphere, freshwater, marine water, soil, even in ice blokes in Antarctica (Xue et al. 2016). They are generally classified according to their origins such as those based on natural sources, or anthropogenic sources including combustion of fossil fuels, vehicle exhaust emissions, pharmaceutical and cosmetic industry, and domestic wastes (Kumar et al. 2016). Adverse effects of PAHs were addressed for various organisms in the marine ecosystem starting from the lowest tropic level with planktons (Tao and Liu 2019), continuing with mussels, (Benali et al. 2017), fishes (Li et al. 2019), cephalopods (Ke et al. 2017), and ending with the humans (Rengarajan et al. 2015; Balcıoğlu 2016; Ke et al. 2017). Sixteen PAHs are specified as priority pollutants by European Commission and US Environmental Protection Agency (EPA) (Xia et al. 2012).

Even though their ubiquitous existence in the water column, biota, and sediments, the detection and monitoring of PAHs in the marine environment is quite challenging due to their strong hydrophobic character. The water solubility of PAHs is known to decrease with increasing $\mathrm{K}_{\mathrm{ow}}$ values, which makes it harder to detect their freely dissolved concentrations when the $\log \mathrm{K}_{\mathrm{ow}}$ value is higher than 5.5. The main method to determine the concentrations of PAHs in the water column is still conventional grab sampling as indicated in the Water Frame Directive (WFD) (European Commission 2009). However, detection of organic pollutants by grab sampling requires a huge amount of water sampling, several pre-treatments, and concentration steps yet only provides the instantaneous concentration of the chemicals in the water column (Allan et al. 2006; Taylor et al. 2019). Moreover, detection of freely dissolved concentrations $\left(\mathrm{C}_{\text {free }}\right)$ of PAHs, which is the regulating parameter for toxicity of the chemicals, is a laborious and complex process, since the suspended materials are also collected during the batch sampling (Reichenberg and Mayer 2006; Booij et al. 2016).

Passive samplers are devices used to overcome the mentioned drawbacks of the conventional batch sampling method. Unlike conventional water sampling, they provide time-averaged concentration of the chemicals and their freely dissolved concentrations $\left(C_{\text {Free }}\right)$ instead of the total ones $\left(C_{\text {Total }}\right)$ (Booij et al. 2016). Being mentioned as a complementary method by WFD, passive sampling of chemicals in the water column is also encouraged by both EPA (Fernandez et al. 2012) and the Oslo-Paris Convention for the protection of the marine environment of the North-East Atlantic (OSPAR) (OSPAR Commision 2013). Since the 1990s, several passive samplers have been developed to detect 
pollutants in marine environments. Different types of samplers were used not only for organic pollutants (Maruya et al. 2015; Belles et al. 2017), but also for heavy metals (Bailon et al. 2019), micropollutants (Mutzner et al. 2020), and biotoxins (Zendong et al. 2016). Although several passive samplers are used to monitor organic pollutants in the marine environment such as polydimethylsiloxane (PDMS) (Jonker et al. 2015), polyoxymethylene (POM) (Josefsson et al. 2015), low-density polyethylene samplers (LDPE) (Estoppey et al. 2016), and butyl rubber (BR) passive samplers (Tureyen et al. 2021), only semipermeable membrane devices (SPMDs) are standardized and commercially available (Huckins et al. 2006; Booij and Smedes 2010). However, a previous study has shown that SPMDs are not able to efficiently sample PAHs with high log $\mathrm{K}_{\text {ow }}$ values (Karacik et al. 2013) and the presented study have found similar results not only for SPMDs but also for PDMS samplers.

BR sorbents were recently introduced into literature to collect petroleum products from oil spills in marine environments, and to remove PAHs from aqueous solutions (Ceylan et al. 2009). More recently, their use as passive samplers was studied in lab-scale experiments in terms of sampling parameters like absorption rates and capacities, and the effects of the pore morphologies and the porosities of the BR samplers on their passive sampling performances were analyzed (Yetiskin et al. 2019; Tureyen et al. 2021).

In the present study, a field survey in Istinye Bay, Istanbul was conducted to analyze and compare the performance of BR passive samplers with SPMDs and PDMS samplers. We demonstrate here the lack of abilities of both SPMD and PDMS samplers to collect PAHs exhibiting a high log $\mathrm{K}_{\mathrm{ow}}$ and hence, high molecular weights. We also found that the BR samplers show the same or higher performances for sampling all sixteen PAHs as compared to the reference commercial samplers. The capability of BR sorbents to sample all PAHs for short and long periods is promising for their use as passive samplers for marine environments.

\section{Materials And Methods}

\section{Materials}

SPMDs of $91.4 \mathrm{~cm} \times 2.5 \mathrm{~cm} \times 70-95 \mu \mathrm{m}$ in dimensions were obtained from Exposmeter (Sweden). The samplers contain $1 \mathrm{~mL}$ triolein spiked with Performance Reference Compounds (PRCs) of phenanthrene-d10, acenaphthene-d10, chrysene-d12, and fluorene-d10, benzo(e)pyrene-d12 (2 $\mu \mathrm{g}$ / SPMD). Another commercial passive sampler PDMS (kSil GP60) used as a reference was supplied from Silicone Engineering Ltd. (Blackburn, UK). Soxhlet extraction was used to clean PDMS samplers with ethyl acetate for 5 days. Both PDMS and BR samplers were prepared with the size of $2 \mathrm{~cm}$ width and $20 \mathrm{~cm}$ length.

BR passive samplers with single network (SN5 and SN10), double network (DN), and triple network (TN) structures were fabricated as detailed before (Muslumova et al. 2019). Briefly, to prepare SN5 and SN10 passive samplers, 5 and $10 \mathrm{~g}$ purified BR was first dissolved in $100 \mathrm{~mL}$ benzene at room temperature overnight, to obtain 5 and $10 \mathrm{w} / \mathrm{v} \% \mathrm{BR}$ solutions respectively. Then, $\mathrm{S}_{2} \mathrm{Cl}_{2}$ ( $6 \mathrm{v} / \mathrm{w} \%$ with respect to $\mathrm{BR}$ ) was added to homogeneous $\mathrm{BR}$ solutions as a crosslinker and the solutions were then stirred for about $2 \mathrm{~min}$. After pouring the reaction solutions into several sealed trays, they were exposed to $-18{ }^{\circ} \mathrm{C}$ for $24 \mathrm{~h}$ for the cryogenic vulcanization (cryogelation) of the BR, which endows to passive samplers their macroporous architectures.

DN and TN passive samplers were prepared via successive cryogelation reactions conducted within the pores of the previous ones. Thus, in order to prepare DN passive samplers, a dried SN5 passive sampler in the sheet geometry was immersed in $10 \mathrm{w} / \mathrm{v} \% \mathrm{BR}$ solution containing $\mathrm{S}_{2} \mathrm{Cl}_{2}$ crosslinker until the swelling equilibrium. Then SN5 passive sampler sheets whose pores were filled with that BR solution were put in $-18{ }^{\circ} \mathrm{C}$ for $24 \mathrm{~h}$ to conduct the cryogelation reactions of the second network within the pores of the first network. TN passive samplers were prepared with the 
same approach, i.e., via the cryogelation of the third network within the pores of the second network after immersing of a dried DN passive sampler sheet in the same BR solution (10 w/v\%).

\section{Study Area and Sampling Process}

Istinye Bay in the Istanbul Strait with exact coordinates of $41^{\circ} 06^{\prime} 49.0^{\prime \prime}$ and N $29^{\circ} 03^{\prime} 16.5^{\prime \prime}$ E was chosen as the study area. The selected area has busy marine and city traffic, high domestic waste discharge through the Istinye Stream, and also hosted a high functioning shipyard for decades making the area having a high potential for PAH pollution. Previous studies conducted in the same area investigated the PAH content in the marine sediments and water column, and therefore the PAH level history is well known (Karacik et al. 2009, 2013; Barut et al. 2016; Yılmaz et al. 2019).

All passive samplers placed in special stainless steel cages were deployed in a water column of $2 \mathrm{~m}$ depth and $5 \mathrm{~m}$ above the bottom. They were collected after 7 and 14 days. Deployment and collection of the cages were conducted with fields blanks for each type of passive samplers to detect any possible contamination in the processes. All samples were immediately transferred to the laboratory after retrieval in ice bags and stored at $-20^{\circ} \mathrm{C}$ until further analysis.

\section{PAHs Content Analysis of the Samplers}

To determine the PAH contents, samplers were placed into glass vials, and PAHs were extracted with $120 \mathrm{~mL}$ of $\mathrm{n}$ hexane/acetone mixture (3:1 v/v) in a horizontal shaker at $120 \mathrm{rpm}$ for $24 \mathrm{~h}$. That process was repeated three times. The extracts were then collected in flasks and concentrated to a volume of $5 \mathrm{~mL}$ using a rotary evaporator.

The concentrated extracts were purified with column chromatography using $10 \mathrm{~g}$ silica gel and $25 \mathrm{~mL}$ hexane/dichloromethane (3:2, v/v) as the elution mixture. The eluants were then re-concentrated to $5 \mathrm{~mL}$ using a rotary evaporator. The concentrated extracts were transferred to HPLC vials for solvent exchange to acetonitrile under gentile nitrogen flow. PAH contents of the extracts were analyzed with high-performance liquid chromatography (Agilent Technologies 1260 Infinity HPLC). The chromatography conditions were set at an injection volume of $10 \mu \mathrm{L}$, column temperature of $25^{\circ} \mathrm{C}$, flow rate of $0.850 \mathrm{~mL} / \mathrm{min}$, and excitation wavelength of $260 \mathrm{~nm}$. Water:acetonitrile (\%/\%) mobile phase gradient was as follows: 60:40 (0-17 $\mathrm{min})$, 0:100 (17-25 min), and 60:40 (27-30 min).

\section{Quality control and data handling}

In order to secure the data precision, sampling activities were conducted with 2 replicates for each passive sampler, and averaged results with standard deviations are given. The extraction and purification processes of the samples were examined in terms of the recovery rate with 9,10-Dimethylanthracene as the surrogate standard. PAH concentrations of the samplers were calculated by taking the site and laboratory contamination into account with field blank and laboratory blank samplers. The comparison of the passive samplers performances was conducted with recovery and weight corrections, and the results were given per unit gram of samplers.

\section{Results And Discussions}

Individual and total concentrations of PAHs in the six different passive samplers for 7 days and 28 days are given in Table 1 and Figure 1. Only results for 14 PAHs out of 16 could be measured due to analytic problems. Table 1 reveals that all samplers show similar sampling performances for acenaphthene (AC), fluorene (FL), phenanthrene (PHE), anthracene (AN), fluoranthene (FA), and pyrene (PY) although the sampled levels are diverse. On the other hand, both for 7 days and 28 days, PAHs with a log $\mathrm{K}_{\mathrm{ow}}$ value of higher than 5.2 could have not been collected by PDMS samplers. 
Table 1

Individual PAH concentrations in passive samplers ( $\mathrm{ng} / \mathrm{g}$ ) used in Istinye Bay.

\begin{tabular}{|c|c|c|c|c|c|c|c|c|c|c|c|c|}
\hline & $\begin{array}{l}\text { PDMS- } \\
7\end{array}$ & $\begin{array}{l}\text { PDMS- } \\
28\end{array}$ & $\begin{array}{l}\text { SN5- } \\
7\end{array}$ & $\begin{array}{l}\text { SN5- } \\
28\end{array}$ & $\begin{array}{l}\text { SN10- } \\
7\end{array}$ & $\begin{array}{l}\text { SN10- } \\
28\end{array}$ & $\begin{array}{l}\text { DN- } \\
7\end{array}$ & $\begin{array}{l}\text { DN- } \\
28\end{array}$ & $\begin{array}{l}\text { TN- } \\
7\end{array}$ & $\begin{array}{l}\text { TN- } \\
28\end{array}$ & $\begin{array}{l}\text { SPMD- } \\
7\end{array}$ & $\begin{array}{l}\text { SPMD- } \\
28\end{array}$ \\
\hline$A C$ & 19.2 & 7.7 & 22.8 & 27.4 & 15.4 & 15.5 & 15.8 & 23.2 & 18.3 & 14.6 & 40.6 & 44.8 \\
\hline $\mathrm{FL}$ & 27.4 & 28.6 & 17.7 & 20.1 & 11.8 & 15.6 & 16.2 & 15.9 & 9.6 & 14.9 & 22.5 & 27.6 \\
\hline PHE & 26.4 & 90.6 & 39.0 & 82.8 & 27.7 & 50.3 & 25.5 & 60.5 & 28.7 & 46.7 & 33.9 & 102.4 \\
\hline AN & 0.2 & 1.5 & 0.9 & 1.7 & 4.2 & 4.0 & 1.7 & 4.2 & 2.3 & 2.4 & 5.0 & 5.8 \\
\hline FA & 7.3 & 25.5 & 14.1 & 32.8 & 12.7 & 18.8 & 8.5 & 31.7 & 9.2 & 14.6 & 15.1 & 57.2 \\
\hline PY & 6.8 & 43.4 & 14.3 & 51.1 & 11.0 & 26.9 & 8.1 & 40.5 & 7.8 & 20.6 & 17.3 & 77.0 \\
\hline $\mathrm{BaA}$ & $\mathrm{bdl}^{*}$ & bdl & 3.9 & 2.1 & 7.5 & 7.2 & 3.8 & 11.4 & 3.6 & 3.8 & 19.6 & 19.7 \\
\hline $\mathrm{CHR}$ & 0.4 & 0.6 & 4.6 & 8.8 & 7.8 & 8.4 & 3.8 & 8.0 & 3.3 & 5.0 & 11.9 & 12.3 \\
\hline BbFA & bdl & 0.5 & 4.7 & 7.7 & 6.9 & 7.2 & 4.0 & 17.1 & 3.4 & 4.9 & 15.5 & 18.0 \\
\hline BkFA & bdl & bdl & 2.2 & 2.3 & 6.0 & 5.8 & 3.4 & 7.4 & 2.8 & 3.3 & 5.7 & 5.7 \\
\hline $\mathrm{BaP}$ & bdl & 0.4 & 4.2 & 5.8 & 6.8 & 6.3 & 5.2 & 13.5 & 3.7 & 12.0 & 9.0 & 10.0 \\
\hline DBahA & bdl & bdl & 6.0 & 3.4 & 5.4 & 4.3 & 6.9 & 1.5 & 3.1 & 3.0 & bdl & bdl \\
\hline BghiP & 0.1 & 1.2 & 6.9 & 12.9 & 6.6 & 7.1 & 8.2 & 14.1 & 4.1 & 2.1 & bdl & 0.9 \\
\hline IP & bdl & bdl & 3.5 & 4.6 & 5.1 & 5.2 & 4.9 & 13.8 & 3.5 & 3.3 & 0.7 & 1.9 \\
\hline \multicolumn{13}{|c|}{$\begin{array}{l}\text { Acenaphthene: AC; Fluorene: FL; Phenanthrene: PHE; Anthracene: AN; Fluoranthene: FA; Pyrene: PY; } \\
\text { Benzo(a)anthracene: BaA; Chrysene: CHR; Benzo(b)fluoranthene, BjFA; Benzo(k)fluoranthene: BkFA; } \\
\text { Benzo(a)pyrene: BaP; Dibenzo (a,h)anthracene: DBahA; Benzo(g,h,i)perylene: BghiP; Indeno(1,2,3-c,d)pyrene: IP; } \\
\text { *bdl: below detection limits }\end{array}$} \\
\hline
\end{tabular}

Even though all the samplers apart from PDMS show sufficient performance for most of the PAHs both in 7 days and 28 days of sampling, a significant difference in their performances was observed with PAHs with a log $\mathrm{K}_{\text {ow }}$ value higher than 6.0, namely for dibenzo (a,h)anthracene (DBahA), benzo(g,h,i)perylene (BghiP) and indeno(1,2,3-c,d)pyrene (IP) (three bottom rows in Table 1). These chemicals exhibit the most carcinogenic and mutagenic effects on the organisms (Smith et al. 2010). It is also obvious from Table 1 that these three chemicals are the least sampled PAHs for all the samplers. To highlight this feature, the sampling amounts of DBahA, BghiP, and IP by the passive samples are compared in Figure 2. It is seen that particularly SPMDs and PDMS samplers show poor sampling performances for these PAHs. Specifically, DBahA was not collected at all by both samplers and for both sampling periods. BghiP was sampled by PDMS sampler in both periods while it could only be detected by SPMDs in 28 days samples. IP, on the other hand, was sampled by SPMDs for both periods while has not been collected by the PDMS sampler. Moreover, even when these three PAHs were sampled by PDMS and SPMD samplers, the sampled amounts are relatively low when compared with the BR samplers.

When the performances of BR samplers are compared only among them, no significant differences in their performances were observed although they sampled different amounts of PAHs. However, some analytical problems have been encountered with the SN5 sampler. Since the SN5 sampler has a high surface roughness, it is likely that the suspended materials in the water column were adsorbed to the sampler surfaces. Even though their surfaces, like all other samplers, were gently cleaned after their retrieval, it is considered that this phenomenon may have affected the 
results. Other BR samplers have smoother surfaces which makes it hard for suspended materials to adsorb and hence, no significant amount of these materials were observed in the sampling processes. Moreover, double- and triplenetwork samplers have macropores with different sizes due to the multiple cryogelation processes, which make their production more complex and costly, however, their overall PAH sampling performances are not significantly improved when compared with the single network BR samplers. In the light of these facts, for field studies, the SN10 BR sampler can be considered as the best option among BR samplers. In Figure 3, the sampling performances of the SN10 sampler and the SPMD sampler for the PAHs with different log $\mathrm{K}_{\mathrm{ow}}$ values were compared.

As it can be seen from Figure 3, even though the SPMD sampled higher amounts than the SN10 sampler for the PAHs with low log $\mathrm{K}_{\mathrm{ow}}$ values, its performance decreases dramatically with PAHs with higher hydrophobicity. In fact, they were not able to sample certain chemicals from the water column in this study. On the other hand, SN10 samplers show consistent sampling performances over all $\log \mathrm{K}_{\mathrm{ow}}$ values and are able to sample all of the PAHs. Moreover, the ability to sample all pollutants from water to detect their existence and measure their concentration in the water column is more critical and significant than the sampled amounts due to the fact that after certain amounts of sampling, the sampled amount is irrelevant for calculating the water concentrations of the chemicals. The significant parameters for back-calculating water concentrations of the pollutants are the sampling rates and partition coefficients rather than the "sampled amounts".

\section{Conclusion}

In the previous studies, the performance of the BR sorbent as an alternative passive sampler was determined via laboratory studies, and the results indicated that the use of BR samplers is feasible and promising. In the present study, the PAH sampling ability of a series of BR sorbents was examined in the field studies in Istinye Bay, Istanbul. Four different types of BR sorbents were placed in the water column for 7 and 28 days along with the commercial samplers, SPMD, and PDMS. The collected amounts of PAHs in the samplers were determined in the laboratory, and the results showed that BR samplers have the ability to collect all fourteen PAHs regardless of their log $\mathrm{K}_{\mathrm{ow}}$ values. However, PDMS and SPMD samplers only sampled the chemicals with $\log \mathrm{K}_{\mathrm{ow}}$ values lower than 5.2 and 6.0, respectively. When compared with the bi-phasic structure of the SPMD samplers, the mono-phasic BR sampler also provides more undemanding and effortless analytical procedures in field studies.

Moreover, the present study also indicates that BR samplers with a single network structure, like SN10 sampler, have a sufficient sampling performance for both short- and long-term periods, and should be selected for monitoring studies. It should be noted that only the accumulated amounts of PAHs in the samplers were measured in this study, and the water concentrations of chemicals were not calculated. Further studies to determine partition coefficients of the BR samplers should be conducted primarily to back-calculate the water concentrations.

\section{Declarations}

\section{Acknowledgments}

Part of the present research was initially presented in CEMEPE2021 Conference, July 20 to 24, 2021, Thessaloniki, Greece and the research was funded by the Scientific and Technical Research Council of Turkey (TUBITAK), CAYDAG, 117 Y099.

\section{Funding}

The research was funded by the Scientific and Technical Research Council of Turkey (TUBITAK), CAYDAG, 117 Y099. 


\section{Competing Interests}

The authors have no relevant financial or non-financial interests to disclose.

\section{Author Contributions}

All authors contributed to the study conception and design. Material preparation, data collection and analysis were performed also by all authors. The first draft of the manuscript was written by Oktay Eren Tureyen and all authors commented on previous versions of the manuscript. All authors read and approved the final manuscript.

\section{Data Availability}

The datasets generated during the current study are available from the corresponding author on reasonable request.

\section{References}

1. Allan IJ, Vrana B, Greenwood R et al (2006) A "toolbox" for biological and chemical monitoring requirements for the European Union's Water Framework Directive. In: Talanta. Elsevier

2. Bailon MX, Park M, oh, Hong Y (2019) Passive sampling methods for assessing the bioaccumulation of heavy metals in sediments. Curr Pollut Reports 5:129-143

3. Balcıoğlu EB (2016) Potential effects of polycyclic aromatic hydrocarbons (PAHs) in marine foods on human health: a critical review. Toxin Rev 35:98-105

4. Barut IF, Meriç E, Yokeş MB (2016) Assessment of recent and chalcolithic period environmental pollution using Mytilus galloprovincialis Lamarck, 1819 from Yarimburgaz Cave, the northern Marmara Sea and Bosphorus coasts. Oceanologia 58:135-149

5. Belles A, Alary C, Aminot $Y$ et al (2017) Calibration and response of an agarose gel based passive sampler to record short pulses of aquatic organic pollutants. Talanta 165:1-9

6. Benali I, Boutiba Z, Grandjean D et al (2017) Spatial distribution and biological effects of trace metals (Cu, Zn, Pb, $\mathrm{Cd}$ ) and organic micropollutants (PCBs, PAHs) in mussels Mytilus galloprovincialis along the Algerian west coast. Mar Pollut Bull 115:539-550

7. Booij K, Robinson CD, Burgess RM et al (2016) Passive sampling in regulatory chemical monitoring of nonpolar organic compounds in the aquatic environment. Environ Sci Technol 50:3-17

8. Booij K, Smedes F (2010) An improved method for estimating in situ sampling rates of nonpolar passive samplers. Environ Sci Technol 44:6789-6794

9. Ceylan D, Dogu S, Karacik B et al (2009) Evaluation of butyl rubber as sorbent material for the removal of oil and polycyclic aromatic hydrocarbons from seawater. Environ Sci Technol 43:3846-3852

10. Estoppey N, Schopfer A, Fong C et al (2016) An in-situ assessment of low-density polyethylene and silicone rubber passive samplers using methods with and without performance reference compounds in the context of investigation of polychlorinated biphenyl sources in rivers. Sci Total Environ 572:794-803

11. European Commission (2009) CIS WFD, Guidance Document No. 19,Surface Water Chemical Monitoring

12. Fernandez LA, Lao W, Maruya KA et al (2012) Passive sampling to measure baseline dissolved persistent organic pollutant concentrations in the water column of the Palos Verdes shelf superfund site. Environ Sci Technol 46:11937-11947

13. Huckins JN, Petty JD, Booij K (2006) Monitors of organic chemicals in the environment: semipermeable membrane devices, vol 223. Springer, New York 
14. Jonker MTO, Van Der Heijden SA, Kotte M, Smedes F (2015) Quantifying the effects of temperature and salinity on partitioning of hydrophobic organic chemicals to silicone rubber passive samplers. Environ Sci Technol 49:67916799

15. Josefsson S, Arp HPH, Kleja DB et al (2015) Determination of polyoxymethylene (POM) - water partition coefficients for oxy-PAHs and PAHs. Chemosphere 119:1268-1274

16. Karacik B, Okay OS, Henkelmann B et al (2013) Water concentrations of PAH, PCB and OCP by using semipermeable membrane devices and sediments. Mar Pollut Bull 70:258-265

17. Karacik B, Okay OS, Henkelmann B et al (2009) Polycyclic aromatic hydrocarbons and effects on marine organisms in the Istanbul Strait. Environ Int 35:599-606

18. Ke CL, Gu YG, Liu Q et al (2017) Polycyclic aromatic hydrocarbons (PAHs) in wild marine organisms from South China Sea: Occurrence, sources, and human health implications. Mar Pollut Bull 117:507-511

19. Kumar V, Kothiyal NC, Saruchi et al (2016) Sources, distribution, and health effect of carcinogenic polycyclic aromatic hydrocarbons (PAHs) - current knowledge and future directions. J Chinese Adv Mater Soc 4:302-321

20. Li Y, Wang C, Zou X et al (2019) Occurrence of polycyclic aromatic hydrocarbons (PAHs) in coral reef fish from the South China Sea. Mar Pollut Bull 139:339-345

21. Maruya KA, Lao W, Tsukada D, Diehl DW (2015) A passive sampler based on solid phase microextraction (SPME) for sediment-associated organic pollutants: Comparing freely-dissolved concentration with bioaccumulation. Chemosphere 137:192-197

22. Muslumova S, Yetiskin B, Okay O (2019) Highly stretchable and rapid self-recoverable cryogels based on butyl rubber as reusable sorbent. Gels 5(1):1

23. Mutzner L, Bohren C, Mangold S et al (2020) Spatial differences among micropollutants in sewer overflows: a multisite analysis using passive samplers. Environ Sci Technol 54:6584-6593

24. OSPAR Commision (2013) JAMP Guidelines for Monitoring of Contaminants in Seawater (Agreement 2013-03)

25. Reichenberg F, Mayer P (2006) Two complementary sides of bioavailability: accessibility and chemical activity of organic contaminants in sediments and soils. Environmental Toxicology and Chemistry: An International Journal 25(5):1239-1245

26. Rengarajan T, Rajendran P, Nandakumar N, Lokeshkumar B, Rajendran P, Nishigaki I (2015) Exposure to polycyclic aromatic hydrocarbons with special focus on cancer. Asian Pacific Journal of Tropical Biomedicine 5(3):182-189

27. Smith DC, Smith MJ, White KL Jr (2010) Systemic immunosuppression following a single pharyngeal aspiration of 1, 2: 5, 6-dibenzanthracene in female B6C3F1 mice. J Immunotoxicol 7:219-231

28. Tao Y, Liu D (2019) Trophic status affects the distribution of polycyclic aromatic hydrocarbons in the water columns, surface sediments, and plankton of twenty Chinese lakes. Environ Pollut 252:666-674

29. Taylor AC, Fones GR, Vrana B, Mills GA (2021) Applications for passive sampling of hydrophobic organic contaminants in water-a review. Crit Rev Anal Chem 51(1):20-54

30. Tureyen OE, Yilmaz A, Yakan SD et al (2021) Performance of butyl rubber-based macroporous sorbents as passive samplers. Environ Sci Pollut Res 28:3766-3773

31. Xia K, Hagood G, Childers C et al (2012) Polycyclic aromatic hydrocarbons (PAHs) in Mississippi seafood from areas affected by the deepwater horizon oil spill. Environ Sci Technol 46:5310-5318

32. Xue R, Chen L, Lu Z et al (2016) Spatial distribution and source apportionment of PAHs in marine surface sediments of Prydz Bay, East Antarctica. Environ Pollut 219:528-536

33. Yetiskin B, Tureyen OE, Yilmaz A, Yakan SD, Okay OS, Okay O (2019) Single-, double-, and triple-network macroporous rubbers as a passive sampler. ACS Appl Mater Interfaces 11(31):28317-28326 
34. YIlmaz A, Tolun LG, Okay OS (2019) Pollution and toxicity of sediment in potential dredging sites of the Marmara Sea, Turkey. J Environ Sci Heal - Part A Toxic/Hazardous. Subst Environ Eng 54:1206-1218

35. Zendong Z, Bertrand S, Herrenknecht C et al (2016) Passive sampling and high resolution mass spectrometry for chemical profiling of french coastal areas with a focus on marine biotoxins. Environ Sci Technol 50:8522-8529

Figures

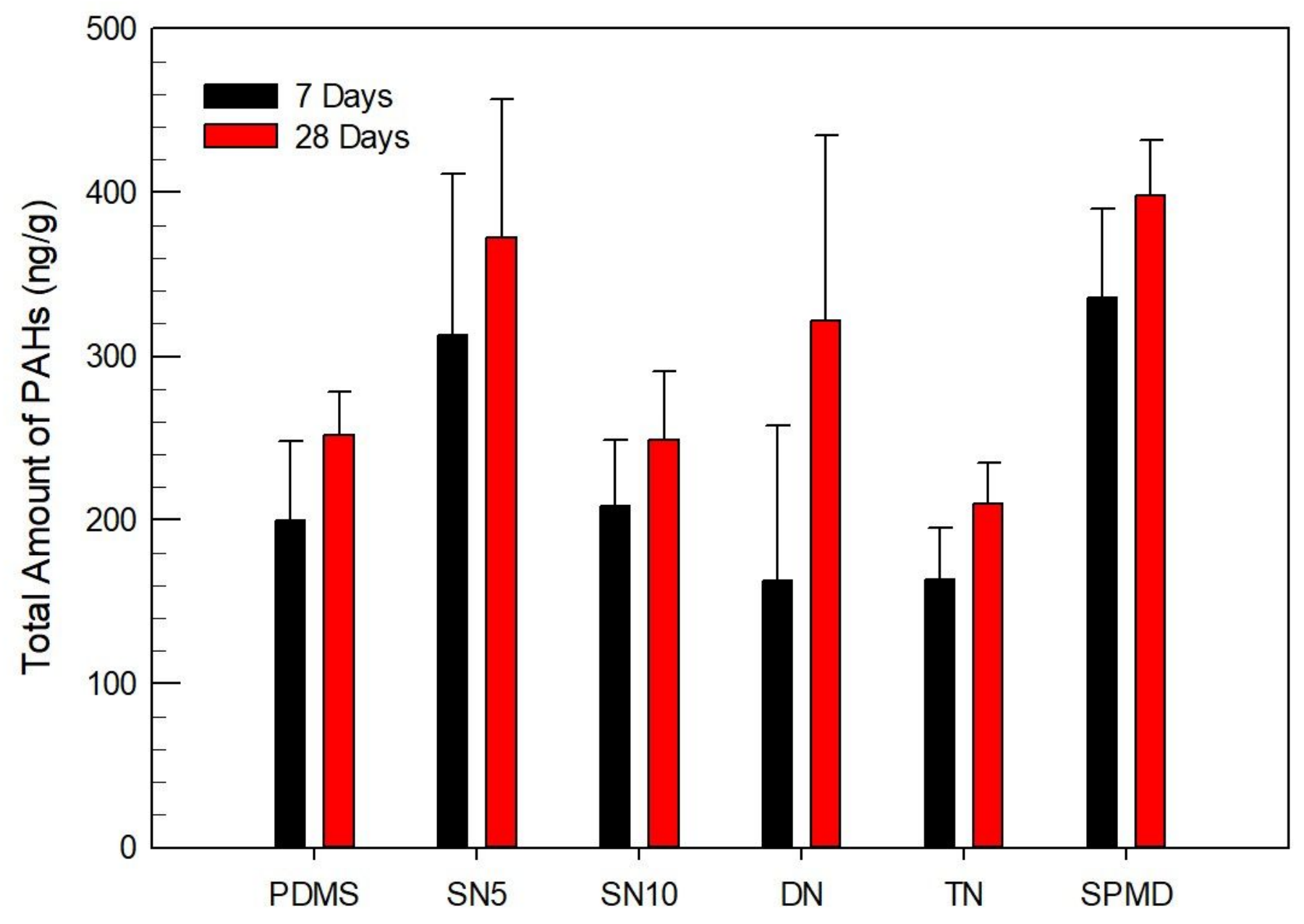

Figure 1

The total amount of sampled PAHs in the samplers. 

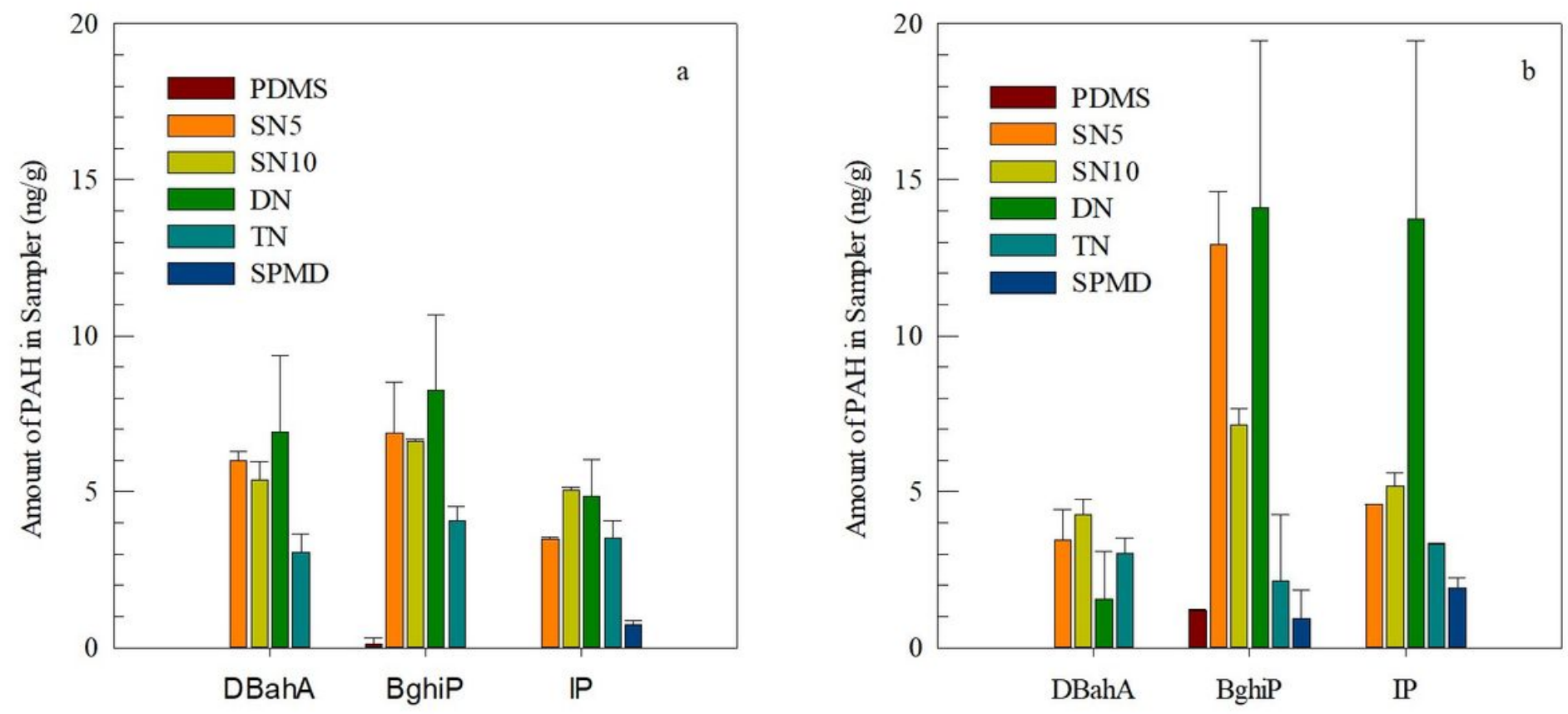

Figure 2

The sampled amount of PAHs with log Kow values higher than 6.0, a) for 7 days sampling period, b) for 28 days sampling period 


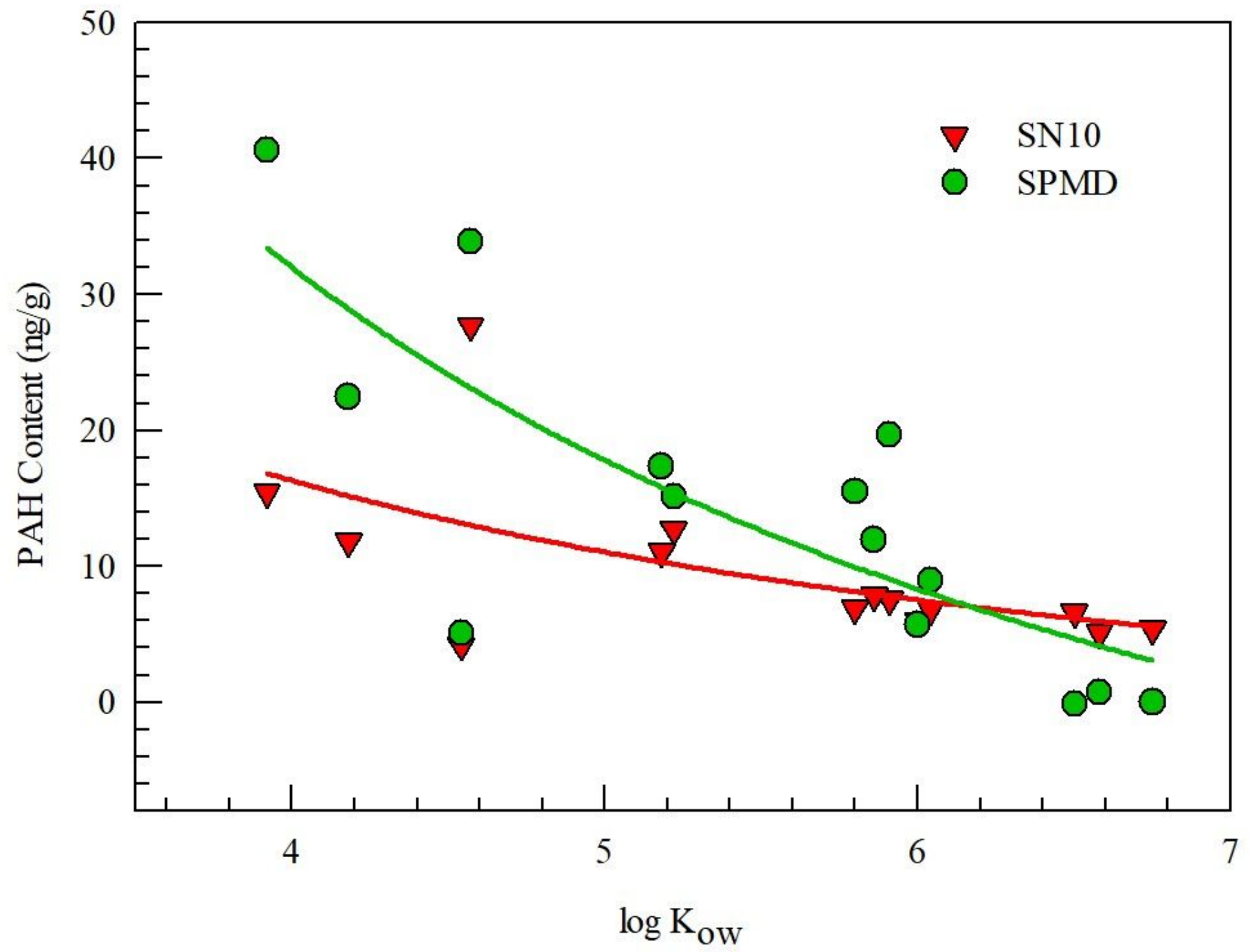

Figure 3

Comparison of SN10 and SPMD sampler performances for different log Kow values. 